\title{
Peripheral circulatory adaptations to pump failure of the heart
}

\author{
Helmut Drexler
}

Impairment of ventricular performance is the initial step in the development of heart failure, but the symptoms and the reduced exercise capacity cannot solely be explained by left ventricular dysfunction. The degree of ventricular dysfunction in congestive heart failure (CHF) does not correlate with its severity - that is, indices of left ventricular dysfunction do not predict or correlate closely with the functional state of patients with $\mathrm{CHF}$ as assessed by exercise tests. ${ }^{1}$ Although right ventricular dysfunction has been linked to the severity of symptoms and exercise intolerance, right ventricular failure seems to be a secondary problem in most cases of clinical systolic heart failure. There is evidence that prognosis is associated with the degree of left ventricular dysfunction, extent of myocardial loss, and cardiac dimensions. Clinical symptoms of heart failure usually emerge with the activation of neurohumoral systems, in particular the sympathetic system and the reninangiotensin system. The study of left ventricular dysfunction (SOLVD) trial confirmed that increases of plasma atrial natriuretic peptide and noradrenalin occur early in the disease and plasma renin activity increases with symptoms. ${ }^{2}$ Although numerous factors are likely to be involved in the development of symptoms, the decrease in renal perfusion may activate the renin-angiotensin system. Experimental data suggest that this alteration of renal haemodynamics emerges early in the course of heart failure. Sodium retention may also emerge early and compensate for impaired left ventricular dysfunction by increasing the preload. One important clinical symptom in chronic heart failure is early fatigue during physical activity, which has
III, Universität Freiburg, Germany H Drexler

Correspondence to: Dr Helmut Drexler, Medizinische Klinik III Universität Freiburg Hugstetterstrasse 55, 79106 Freiburg, Germany. been linked to impaired perfusion of skeletal muscle during exercise. In patients with chronic heart failure, the increase during exercise in blood flow to working muscle and the oxygen consumption are less than those of normal people, whereas plasma lactate concentrations are increased for each given workload. ${ }^{3}$ Most of the reduction in maximal blood flow during exercise occurs in oxidative working muscle. ${ }^{4}$ This impairment of metabolic vasodilatory capacity within skeletal muscle during exercise has often been attributed to excessive sympathetically mediated vasoconstriction, activation of the plasma renin-angiotensin system and more recently to increased concentrations of endothelin (fig 1). ${ }^{5}$ It seems that endothelin concentrations play an important part in the pulmonary circulation $^{6}$ but its pathophysiological relevance in the systemic circulation remains uncertain. Although these neurohumoral factors exert potent systemic and regional vasoconstriction, they do not completely explain the impairment of vasodilating capacity within skeletal muscle in patients with chronic heart failure. Impaired metabolic vasodilatation during exercise cannot be restored by $\alpha$ blockade with phentolamine. ${ }^{78}$ Similarly, a dose of angiotensin converting enzyme (ACE) inhibitor does not restore metabolic vasodilatation to normal despite substantial reductions of plasma angiotensin II and noradrenaline (norepinephrine) concentrations. ${ }^{9}$ This indicates that blockade of the plasma renin angiotensin system by ACE inhibitors does not interfere with blood flow to working muscle during exercise in patients with CHF. ${ }^{910}$ After treatment with an ACE inhibitor for several months, a noteable increase in femoral blood flow during exercise is found and is accompanied by an improved peak oxygen consumption. ${ }^{9}$ Thus, long-term ACE inhibitor treatment reversed the inability of peripheral vessels to dilate. This is consistent with previous findings that the full beneficial effect of ACE inhibitor treatment in large scale trials emerges slowly with time. ${ }^{11}$ Similarly, peripheral perfusion and skeletal muscle function take weeks or months to return to normal after cardiac transplantation.

What are the mechanisms for the delayed beneficial effects of ACE inhibitors or cardiac transplantation? It is important to note that exercise tolerance in patients with heart failure is not determined solely by central haemodynamics. One possible explanation could be that the delayed effect of ACE inhibitors may be partly due to its interference with the

Figure 1 Regional vascular compensatory vasoconstrictor mechanisms in congestive heart failure. 
vascular tissue renin-angiotensin system, which reverses chronic structural alteration of the vessel. Experimental evidence indicates that angiotensin II induces hypertrophy of cultured rat aortic smooth muscle cells. ${ }^{12}$ Angiotensin II, endothelin, and noradrenaline seem to be involved in the activation of protooncogenes. ${ }^{13}$ This suggests that angiotensin II may be involved in the proliferative process of tissues during growth (endogenous growth factor). Recent findings indicate that ACE inhibition can reverse structural vascular alteration in a rat model of hypertension ${ }^{14}$ to a greater extent than can other antihypertensive drugs. ${ }^{15}$

Unfortunately, experimental and clinical studies investigating structural alterations in chronic heart failure are scarce and contradictory. Although some studies have indicated that structural abnormalities might occur at the level of the resistance vessel ${ }^{16}$ others did not show such alterations. ${ }^{17}$ The clinical studies usually have been confined to skin resistance vessels and may not be representative of skeletal muscle resistance vessels. Small biopsies of skeletal muscle often allow examination of only very small arterioles $(<50 \mu \mathrm{m})$, which may not play the main part in regulating blood flow. This seems also to be true of resistance vessels that range from 80-200 $\mu \mathrm{m}$. Other potential mechanisms involved in the impairment of metabolic peripheral dilatation in chronic heart failure include a vascular stiffness component owing to the increased vascular sodium content, which can be partly reduced with diuretic treatment in decompensated heart failure. ${ }^{18}$ Although it remains controversial whether structural changes occur in the microcirculation of skeletal muscle, flow dependent dilatation, and dilatation of large conduit vessels induced by glyceryl trinitrate are impaired in patients with heart failure indicating that these patients have impaired relaxation of vascular smooth muscle and have impaired elastic properties of the large conduit vessels. ${ }^{19}$ This may have functional consequences through a negative feedback on the pumping performance of the left ventricle.

\section{Endothelial dysfunction}

The pivotal role of the endothelium derived relaxing factor on vascular tone is now recognised. Nitric oxide, which accounts for most of the biological activity of endothelium derived relaxing factor, is continuously released from the endothelium, and this basal release of nitric oxide provides a constant counteracting force to vasoconstrictor substances such as noradrenaline or angiotensin II. Secondly, endothelium derived relaxing factor can be released from the endothelium upon stimulation - that is, by bradykinin or ADP. Several pathophysiological conditions such as hypercholesterolaemia or hypertension are associated with dysfunctional endothelium - that is, either the basal or stimulated release of endothelium derived relaxing factor is altered. Recent data from our labora- tory and others showed that endothelium dependent relaxation of the microcirculation of skeletal muscle in response to acetylcholine is impaired in chronic heart failure whereas the vasodilating effect of glyceryl trinitrate is preserved. ${ }^{20-22}$ Although the functional importance of this finding remains unclear, it seems likely that endothelial dysfunction in the peripheral circulation is involved in the impairment of both reactive hyperaemia and increase in blood flow in heart failure. Studies on the coronary circulation have shown that inhibition of the synthesis of nitric oxide reduces the total reactive hyperaemia.

The basal release of nitric oxide, which accounts for the biological activity of endothelium derived relaxing factor, ${ }^{23}$ has been shown to contribute to the control of regional blood flow in humans by the use of $\mathrm{N}$-monomethylL-arginine (L-NMMA), a selective inhibitor of nitric oxide from L-arginine. ${ }^{24}$ In the absence of notable vasoconstriction of conduit vessels, changes in blood flow indicate the response of resistance vessels. To identify the endothelium dependent vasomotor response of large forearm conduit $v$ small resistance vessels we used a novel ultrasound device to determine forearm arterial diameter accurately. ${ }^{25}{ }^{26}$ Simultaneously, blood flow velocity was recorded by a Doppler velocity device in the same vessel. By this method, the effects of intra-arterial infusion of acetylcholine, LNMMA, and glyceryl trinitrate on forearm conduit and resistance vessels were examined in patients with chronic CHF and age matched healthy volunteers. Although the blood flow response to acetylcholine was blunted in patients with CHF, the decrease in flow induced by L-NMMA was enhanced and the response to glyceryl trinitrate was preserved. $^{21}$ As L-NMMA inhibits the basal release of nitric oxide, an exaggerated vasoconstrictor response in patients with heart failure (compared with controls) is consistent with the notion that the basal release of nitric oxide is increased in the peripheral circulation of patients with heart failure. Thus, endothelium dependent dilatation of forearm resistance vessels is impaired in patients with CHF, suggesting a reduced stimulated release of nitric oxide in response to acetylcholine. The basal release of nitric oxide seems to be enhanced, however, in a compensatory manner. As the dilator response to both acetylcholine and glyceryl trinitrate involves the activation of the guanylate cyclase system (or a non-specific effect of opposing constrictor forces) a generalised defect within the guanylate cyclase system cannot account for this finding. Thus in patients with heart failure, the stimulated release of endothelium derived relaxing factor seems to be attenuated resulting in an impaired endothelium dependent relaxation of resistance vessels. This does not establish a general impairment of endothelial function or specifically an impairment of the basal release of nitric oxide synthesised from L-arginine. Indeed, blood flow after a high dose of L-NMMA was even more reduced in patients with $\mathrm{CHF}$ than in normal people. 


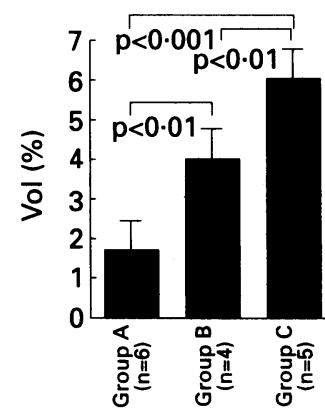

Figure 2 Volume density of mitochondria with cytochrome c oxidase positive cristae. Group $A$ patients with severe heart failure; group $B$, patients with moderate heart failure; group $C$, normal controls.
Thus it seems that the stimulated and basal release of nitric oxide are dissociated in patients with heart failure. The basal release of nitric oxide seems to be preserved or may even be enhanced in the peripheral circulation whereas the stimulated endothelial dependent dilatation exerted by acetylcholine is blunted. The finding that forearm blood flow was substantially reduced with L-NMMA without important changes in the diameters of large conductance vessels in normal people suggests a preferential release or activity of nitric oxide in forearm resistance vessels compared with large conductance vessels in humans. Thus the basal release of nitric oxide seems to play an important part in modulating tissue perfusion in distal resistance vessels in the forearm in heart failure but may be negligible in conduit vessels, or other factors may override this effect on vasomotor tone in large arteries.

Experimental evidence shows that longterm treatment with ACE inhibitors and physical training improve endothelial dysfunction in experimental heart failure. ${ }^{27}$ Preliminary data indicate that training can improve endothelial function in patients with heart failure. ${ }^{28}$ The beneficial effect of ACE inhibitors on endothelial function might be due to the inhibition of the breakdown of bradykinin, which is degraded by ACE. ${ }^{29}$ Inhibition of the ACE mechanism may increase the local tissue concentrations of bradykinin, which in turn stimulates the release of nitric oxide (which accounts for the biological activity of the endothelium derived relaxing factor) and vasodilating prostaglandins. ${ }^{29} 30$

\section{Intrinsic alterations of skeletal muscle in chronic heart failure}

Although acute doses of vasodilators or positive inotropes may improve blood flow to skeletal muscle during exercise, duration of exercise and maximal oxygen consumption do not increase immediately after these drugs are given. ${ }^{31}$ This indicates that oxygen uptake within skeletal muscle during exercise cannot be improved during short-term intervention in patients with chronic heart failure even when oxygen delivery is enhanced. This finding suggests that blood flow is shunted away from active muscle or that there are intrinsic alterations of skeletal muscle in chronic heart failure, or both. We have noted previously that there might be a shift from oxidative skeletal muscle to activation of more glycolytic working muscle fibres ${ }^{4}$ again indicating a change in the properties of the skeletal muscle itself. Muscle biopsies taken from patients with chronic heart failure showed moderate atrophy (reduced muscle mass) and biochemical alterations including a shift in the distribution of fibre type in skeletal muscle. ${ }^{32} 33$ Ultrastructural analysis of skeletal muscle biopsy specimens has shown a reduced oxidative capacity of the muscle as indicated by a reduced volume, density, and reduced surface area of the cristae of mitochondria. ${ }^{34}$
Cytochrome c oxidase staining of the ultrastructural and biochemical measurement of citrate synthase showed a significantly reduced concentration of the oxidative enzymes (fig 2), ${ }^{34}{ }^{35}$ which suggests that the oxidative capacity of skeletal muscle is diminished in severe chronic heart failure. In fact, a close relation has been found between the oxidative capacity of working muscle, as assessed by cytochrome c oxidase or cristae surface density of mitochrondria within the skeletal muscle and the peak oxygen consumption during exercise. ${ }^{3436}$ Thus exercise capacity seems to be partly determined by the condition of the working muscle. ${ }^{37}$ The pattern obtained by nuclear magnetic resonance spectroscopy showed abnormal metabolism of skeletal muscle, which supported the ultrastructural and biochemical findings. ${ }^{38}$ With nuclear magnetic resonance spectroscopy, it was shown that the intracellular $\mathrm{pH}$ values during exercise are much lower for a given workload in patients with severe heart failure. Moreover, during exercise, the concentrations of plasma inorganic phosphate and phosphocreatinine decreased much faster in patients with heart failure than in normal people. ${ }^{38} 39$

\section{Potential underlying mechanisms of} peripheral adaptations

Many experimental and human studies have shown that exercise training induces important adaptations in skeletal muscle. ${ }^{40}$ These include increases in capillary supply, muscle mass, mitochondrial content including increased activity of oxidative enzymes, and a shift in the distribution of fibre types-that is, a higher percentage of type I and IIA muscle fibres that possess a higher oxidative capacity than type IIB fibres. This adaptation of skeletal muscle to training results in an increased respiratory capacity of the muscle fibres accompanied by metabolic consequences, such as slower use of muscle glycogen, greater reliance on fat oxidation, and lower lactate production during exercise of a given intensity. ${ }^{40}$ In contrast, during prolonged immobilisation, oxidative enzymes of skeletal muscle, muscle mass, and capillary density all decrease below baseline values. ${ }^{41-43}$ As patients with chronic heart failure usually restrict their physical activity, in part based on their physicians' advice, the hypothesis has been put forward that a deconditioning effect occurs in their skeletal muscle. ${ }^{44}$ Consistent with this concept, bicycle training in patients with chronic heart failure has been shown to improve exercise tolerance by peripheral mechanisms-for example, by delaying the onset of anaerobic metabolism. ${ }^{45}$ Training induced improvement of peripheral muscle metabolism seems to be independent of systemic adaptations. Both in normal people and patients with heart failure, an exercise programme restricted to small muscle groups (such as forearm muscles) improves the metabolic state of skeletal muscle without altering cardiac performance. ${ }^{46}$ 
Although these findings suggest that the alterations in skeletal muscle of patients with chronic heart failure are due to deconditioning, other potential factors should not be dismissed. Mancini et al suggest that decreased caloric and protein intake may be a main contributor to skeletal muscle atrophy. ${ }^{32}$ It would be interesting to see whether or not there is a relation between indices of muscle atrophy and caloric intake. Depressed caloric intake may be an important factor in certain subsets of patients, particularly patients with alcoholic cardiomyopathy. Given the frequent lack of signs of malnutrition, however, other factors are likely to be involved in the development of muscle abnormalities. These factors may include increased free radical activity, ${ }^{47}$ increased sympathetic tone, or monocyte activation associated with increased plasma concentrations of tumour necrosis factor. ${ }^{48} 49$ This monocyte activation, possibly linked to a stimulated renin-angiotensin system in severe heart failure, ${ }^{49}$ may cause endothelial dysfunction $^{50}$ and adversely affect muscle metabolism and function. ${ }^{51}$ Indeed, there is evidence that in patients with cardiac cachexia the net negative protein balance across leg tissue is associated with an increased rate of myofibrillar protein breakdown. ${ }^{52}$ Endothelial dysfunction, which has been shown to emerge in patients with heart failure, ${ }^{21}$ may further compromise skeletal muscle function by affecting its blood flow. Long-term ACE inhibition improves blood flow to skeletal muscles and oxygen extraction during exercise. ${ }^{9}$ Also, preliminary data indicate that ACE inhibitors partially reverse ultrastructural abnormalities of skeletal muscle in patients with heart failure. ${ }^{34}$ Experimental evidence suggests that longterm ACE inhibitor treatment reduces vascular infiltration by monocytes and macrophages and restores endothelial function. ${ }^{5354}$ Some of these findings support the view that alterations of skeletal muscle in heart failure are, after all, the consequence of impaired cardiac function. It has been speculated, however, that a generalised myopathy may occur in a subset of patients with dilated cardiomyopathy. ${ }^{55} 56$ Dunnigan et al found that young patients with cardiomyopathy who developed either ventricular tachycardia or heart failure have histological abnormalities of skeletal and cardiac muscle, in particular, atrophy of type II skeletal muscle fibres. ${ }^{55}$ Caforio et al reported histological alterations characterised by selective atrophy of type 1 fibres, that are similar to those found in congenital and idiopathic myopathies and are unrelated to cardiac functional New York Heart Association classes. ${ }^{56}$ Thus, common underlying factorsfor example, genetic or autoimmune disorders-that affect both cardiac and skeletal muscle may be operating in a subset of patients with dilated or hypertrophic cardiomyopathy. These divergent morphological findings are based on qualitative histological and ultrastructural analysis of upper arm skeletal muscle in a limited number of young patients without clinically overt myopathy..$^{556}$ In contrast, in most reports evaluating weight bearing calf muscle, the abnormalities were similar in patients with heart failure whether due to coronary artery disease or to dilated cardiomyopathy, suggesting that in most cases the reduced oxidative capacity of skeletal muscle is related to the state of heart failure and its severity.

The impact of impaired blood flow during exercise on these skeletal muscle alterations remains unclear. Subsequent studies with nuclear magnetic resonance spectroscopy as well as skeletal muscle function tests in patients with chronic heart failure showed that these abnormalities, under ischaemic conditions, were unrelated to different rates of blood flow to the working muscle during exercise. ${ }^{57-59}$ This does not exclude the fact that repeated episodes of reduced blood flow within skeletal muscle may be involved in the development of skeletal muscle alterations, despite the fact that these alterations, once developed, can be shown regardless of measured flow during the assessment of muscle function ${ }^{59}$ or metabolism..$^{57} 58$

The alterations of the peripheral circulation in chronic heart failure are similar to those found after prolonged physical inactivity. In contrast, opposite changes can be found after intense training - that is, in athletes. Several small studies have documented that a training programme can reverse at least some of the adverse peripheral changes. ${ }^{45} 60$ Based on the theoretical considerations, physical training has a great potential to improve the clinical state of patients with heart failure. Before widespread recommendations can be made the safety of training in patients with heart failure needs to be shown in large populations of patients. In particular, the impact of physical training on cardiac function needs to be tested vigorously. Although some animal studies by Scheuer et al indicate that training may improve the myocardial phenotype and improve cardiac performance, these studies were almost exclusively performed in rats. ${ }^{6162}$ The myocardium of rats has specific properties distinct from the human myocardium, and more importantly, coronary artery disease in humans usually complicates matters. In the end, there may be an interaction between cardiac performance during exercise and the progressive perfusion deficit in skeletal muscle during exercise. It is now established that the force frequency relation is substantially altered in human heart failure-that is, twitch tension of the failing heart decreases with increased heart rate (peak twitch tension 50-70 beats/min), whereas the peak twitch tension in the normal myocardium is 130 to 140 beats $/ \mathrm{min}$. Thus the increase in heart rate in normal people during exercise is associated with increased cardiac output but this myocardial inotropic reserve cannot be recruited in the failing heart and may be involved in the impaired perfusion during exercise. Recent data from our laboratory indicate that the impaired force frequency relation during exercise is related to an altered cardiac phenotype of the expression of the sarcoplasmatic reticulum ATPase. Future 
studies, by integrating cardiac, pulmonary, reflex, vascular, and skeletal muscular aspects should be able to delineate the composite alterations responsible for the clinical syndrome of heart failure.

1 Franciosa JA, Park M, Levine B. Lack of relation between exercise capacity and indices of resting left ventricular performance in heart failure. Am $f$ Cardiol 1981;47: 33-9.

2 Francis GS, Benedict C, Johnstone DE, et al. Comparison of neuroendocrine activation in patients with left ventricular dysfunction with and without congestive heart failure. A substudy of the studies of left ventricul
dysfunction (SOLVD). Circulation 1990;82:1724-9.

3 Zelis R, Longhurst J, Capone RJ, Mason DT. A comparison of regional blood flow and oxygen utilization durin dynamic forearm exercise in normal subjects and patients with congestive heart failure. Circulation

4 Drexler $H$, Faude F, Höing $S$, Just $H$. Blood flow distribution within skeletal muscle during exercise in the presence of chronic heart failure: effect of milrinone. Circulation 1987;76:1344-52.

5 McMurray JJ, Ray SG, Abdullah I, Dargie HJ, Morton JJ Plasma endothelin in chronic heart failure. Circulation 1992;85:1374-9.

6 Giaid A, Yanagisawa M, Langleben D, Michel RP, Levy $R$, Shennib $H$, et al. Expression of endothelin-1 in the lungs of patients with pulmonary hypertension. $N$ Engl 9 Med 1993;328:1732-9.

7 Zelis R, Mason DT, Braunwald E. A comparison of the effects of vasodilator stimuli on peripheral resistance vessels in normal subjects and patients with congestive heart failure. $\mathcal{F}$ Clin Invest 1968;47:960-70.

8 LeJemtel TH, Maskin CS, Lucido D, Chadwick BJ Failure to augment maximal limb blood flow in response to one leg versus two-leg exercise in patients with sever heart failure. Circulation 1986;74:245-51.

9 Drexler $H$, Banhardt U, Meinertz T, Wollschläger $H$, Lehmann $M$, Just $H$. Contrasting peripheral short-term and long-term effects of converting enzyme inhibition in patients with congestive heart failure. A double-blind, placebo-controlled trial. Circulation 1989;79:491-502.

10 Wilson JR, Ferraro N. Effect of renin-angiotensin system on limb circulation and metabolism during exercise in patients with heart failure. $¥ \mathrm{Am}$ Coll Cardio patients with

11 Captopril Multicenter Research Group. A placebo-controlled trial of captopril in refractory chronic congestive trolled trial of captopril in refractory chronic con

12 Geisterfer AAT, Peach MJ, Owens GK. Angiotensin II induces hypertrophy not hyperplasia, of cultured rat aortic smooth muscle cells. Circ Res 1988;62:749-56.

13 Naftilan AJ, Pratt RE, Eldridge CS, Lin HL, Dzau VJ. Angiotensin II induces c-fos expression in smooth muscle via transcriptional control. Hypertension 1989;13 706-11.

14 Levy BI, Michel JB, Salzmann J-L, Azizi M, Poitevin P, Safar M, Camilleri JP. Effects of chronic inhibition of converting enzyme on mechanical and structural properties of arteries in rat renovascular hypertension. Circ Res 1988;63:227-39.

15 Sano T, Tarazi RC. Differential structural responses of small resistance vessels to antihypertensive therapy. Small resistance vessels to

16 Wroblewski H, Kastrup J, Norgaard T, Mortensen SA Haunso S. Evidence of increased microvascular resistance and arterior hyalinosis in skin in congestive hear failure secondary to idiopathic dilated cardiomyopathy. Am $\mathcal{F}$ Cardiol 1992;69:769-74.

17 Lindsay DC, Rothery SM, Anand IS, Severs NJ. Increased vascular resistance in chronic heart failure is not due to ultrastructural changes in the vasculature of skeletal muscle [abstract]. Circulation 1992;86:I-285.

18 Sinoway LI, Minotti J, Musch T, Goldner D, Davis D, Leaman D, Zelis R. Enhanced metabolic vasodilation secondary to diuretic therapy in decompensated congestive heart failure secondary to coronary artery disease. Am $\mathcal{F}$ Cardiol 1987;60:107-11.

19 Hayoz D, Drexler H, Münzel T, Hornig B, Zeiher AM Just $\mathrm{H}$, Brunner $\mathrm{HR}$, Zelis R. Flow mediated arterial dilation is abnormal in congestive heart failure. dilation is abnormal in 6 .

20 Drexler H, Lu W. Endothelial dysfunction of hindquarter resistance vessels in experimental heart failure. $\mathrm{Am}$ resistance vessels in experim
Physiol 1992;262: $\mathrm{H} 1640-5$.

21 Drexler $H$, Hayoz D, Münzel T, Hornig B, Just $H$, Brunner HR, Zelis R. Endothelial function in chronic congestive heart failure. Am $f$ Cardiol 1992;69: 1596-601

22 Kubo SH, Rector TS, Bank AJ, Williams RE, Heifetz SM Endothelium-dependent vasodilation is attenuated in patients with heart failure. Circulation 1991;84:1589-96.

23 Palmer RMJ, Ferrige AG, Moncada S. Nitric oxide release accounts for the biological activity of endothelium- derived relaxing factor. Nature 1987;327:524-6.

24 Vallance P, Collier J, Moncada S. Effects of endotheliumderived nitric oxide on peripheral arteriolar tone in man. Lancet 1989;997-1000.

25 Tardy Y, Meister J, Perret F, Brunner HR, Arditi M. Non-invasive estimate of the mechanical properties of peripheral arteries from ultrasonic and photoplethysmographic measurements. Clin Phys Physiol Meas 1991;12: 39-54.

26 Perret F, Mooser V, Hayoz D, Tardy Y, Meister J Etienne JD, et al. Evaluation of arterial compliancepressure curves: effect of antihypertensive drugs Hypertension 1991;18:II-77-83.

27 Lindsay DC, Jiang C, Brunnotte F, Adamopoulos S, Coats AJS, Rajagopalan B, et al. Impairment of endothelium-dependent responses in a rat model of chronic heart failure: effects of an exercise training protocol. Cardiovasc Res 1992;26:694-7.

28 Yuen JL, Bijou R, Galvao M, Levato P, LeJemtel TH. Intense forearm training improves vascular endothelium function in patients with congestive heart failure [abstract]. $\mathcal{F}$ Am Coll Cardiol 1993;21:316A.

29 Wiemer G, Schölkens BA Becker RHA, Busse R Ramiprilat enhances endothelial autacoid formation by inhibiting breakdown of endothelium-derived bradyinhibiting breakdown of endothelium

30 Mombouli J-V, Naphtali M, Vanhoutte PM. Effects of the converting enzyme inhibitor cilazaprilat on endotheliumdependent responses. Hypertension 1991;18(suppl II): II-22-9.

31 Wilson JR, Martin JL, Ferraro N, Weber KT. Effect of hydralazine on perfusion and metabolism in the leg during up-right bicycle exercise in patients with heart failure. Circulation 1983;68:425-32.

32 Mancini DM, Walter G, Reichek N, Lenkinski R, McCully KK, Mullen JL, Wilson JR. Contribution of skeletal muscle atrophy to exercise intolerance and altered muscle metabolism in heart failure. Circulation 1992;85:1364-73.

33 Lipkin DP, Jones DA, Round JM, Poole-Wilson PA Abnormalities of skeletal muscle in patients with chronic heart failure. Int $f$ Cardiol 1988;18:187-95.

34 Drexler H, Riede U, Münzel T, König H, Funke E, Jus $\mathrm{H}$. Alterations of skeletal muscle in chronic heart failure. Circulation 1992;85:1751-9.

35 Sullivan MJ, Green HJ, Cobb FR. Skeletal muscle biochemistry and histology in ambulatory patients with long-term heart failure. Circulation 1990;81:518-27.

36 Drexler $H$. The effect of ace-inhibitors on the periphera circulation in heart failure. Am F Cardiol 1992;70:50C 4C.

37 Drexler $H$. Skeletal muscle failure in heart failure. Circulation 1992;85:1621-3.

38 Wilson JR, Fink L, Maris J, Ferraro N, Power-Vanwart J, Eleff S, Chance B. Evaluation of energy metabolism in skeletal muscle of patients with heart failure with gated phosphorus-31 nuclear magnetic resonance. Circulation phosphorus-31

39 Massie BM, Conway M, Yonge R, Frostick S, Sleight $P$ Ledingham J, et al. 31P nuclear magnetic resonance evidence of abnormal skeletal muscle metabolism in patients with congestive heart failure. Am $\mathcal{F}$ Cardio 1987;60:309-15.

40 Holloszy JO, Coyle EF. Adaptations of skeletal muscle to endurance exercise and their metabolic consequences. f Appl Physiol 1984;56:831-8.

41 Sullivan MJ, Binkley PF, Unverferth DV, Ren J-H, Boudoulas H, Bashore TM, et al. Prevention of bedrestinduced physical deconditioning by daily dobutamin infusions. Implications for drug-induced physical conditioning. $\mathcal{f}$ Clin Invest 1985;76:1632-42.

42 Jozsa $L$, Järvinnen $M$, Kvist $M$, Lehto $M$, Mikola $A$ Capillary density of tenotomized skeletal muscles. I. Experimental study in the rat. Eur $\mathcal{f}$ Appl Physiol 1980;44:175-81.

43 Hägomark T, Jansson E, Eriksson E. Fiber type area and metabolic potential of the thigh muscle in man after knee surgery and immobilization. Int of Sports Med $1981 ; 2: 12-7$.

44 Drexler H, Münzel T, Riede U, Just H. Adaptive changes in the periphery and their therapeutic consequences. $A m \mathcal{F}$ Cardiol 1991:67:29C-35C

45 Sullivan MJ, Higginbotham MB, Cobb FR. Exercise training in patients with severe left ventricular dysfunction. Hemodynamic and metabolic effects. Circulation 1988;78:506-15.

46 Minotti JR, Johnson EC, Hudson TL, Zuroske G, Murata G, Fukushima E, et al. Skeletal muscle response to exercise training in congestive heart failure. $\mathcal{F}$ Clin Invest 1990;86:751-8.

47 Belch JJF, Bridges AB, Scott N, Chopra M. Oxygen free radicals and congestive heart failure. $\mathrm{Br}$ Heart $f$ 1991;65:245-8.

48 Kalman J, Levine B, Mayer L, Penn J, Kukin ML, Packe $M$. Prognostic importance of circulating neopterin in $M$. Prognostic importance of circulating neopterin in patients with cardiac cachexia. Circulation 1990;82 (suppl patients with

49 Levine B, Kalman J, Mayer L, Fillit H, Packer $M$ Elevated circulating levels of tumor necrosis factor in severe chronic heart failure. N Engl $f$ Med 1990;323. 236-41.

50 Aoki N, Siegfried M, Lefer AM. Anti-EDRF effect of tumor necrosis factor in isolated, perfused cat carotid 
arteries. Am F Physiol 1989;256:H1509-12.

51 Warren RS, Starnes HF Jr, Gabrilove JL, Oettgen HF, Brennan MF. The acute metabolic effects of tumor necrosis factor administration in humans. Arch Sur 1987;122:1396-400.

52 Morrison WL, Gibson JN, Rennie MJ. Skeletal muscle and whole body protein turnover in cardiac cachexia: influence of branched-chain amino acid administration. influence of branched-chain amin

53 Clozel M, Kuhn H, Hefti $H$. Effects of angiotensin converting enzyme inhibitors and of hydralazine on endothelial function in hypertensive rats. Hypertension 1990;16:532-40.

54 Clozel M, Kuhn H, Hefti H, Baumgartner HR. Endothelial dysfunction and subendothelial monocyte macrophages in hypertension. Effect of angiotensin converting enzyme inhibition. Hypertension 1991;18:132-41.

55 Dunnigan A, Staley NA, Smith SA, Pierpont ME, Judd D Benditt DG, Benson DW. Cardiac and skeletal muscle abnormalities in cardiomyopathy: comparison of patients with ventricular tachycardia or congestive hear failure. $₹ \mathrm{Am}$ Coll Cardiol 1987;10:608-18.

56 Caforio ALP, Rossi B, Risalti R, Siciliano G, Marchetti A, Angnelli $\mathrm{C}$, et al. Type 1 fiber abnormalities in skeletal muscle of patients with hypertrophic and dilated car- diomyopathy: evidence of subclinical myogenic myopathy. $\mathcal{F}$ Am Coll Cardiol 1989;14:1464-73.

57 Wiener DH, Fink LI, Maris J, Jones RA, Chance B, Wilson JR. Abnormal skeletal muscle bioenergetics during exercise in patients with heart failure: role of reduced muscle blood flow. Circulation 1986;73:1127-36.

58 Massie BM, Conway $M$, Rajagopalan $B$, Yonge $R$, Frostick S, Ledingham J, et al. Skeletal muscle metaboFrostick S, Ledingham J, et al. Skeletal muscle metabolism during exercise under ischaemic conditions in congestive heart failure. Evidence for abnormalitie unrelated to blood flow. Circulation 1988;78:320-6.

59 Minotti JR, Christoph I, Oka R, Weiner MW, Wells L, Massie BM. Impaired skeletal muscle function in patients with congestive heart failure. Relationship to systemic exercise performance. $\mathcal{f}$ Clin Invest 1991;88: 2077-82.

60 Coats AKS, Adamopoulos S, Meyer TE, Conway J, Sleight $P$. Effects of physical training in chronic heart failure. Lancet 1990;335:63-6.

61 Scheuer J, Malhorta A, Hirsch C, Capasso J, Schaible TF. Physiologic cardiac hypertophy corrects contractile protein abnormalities associates with pathologic hypertrophy in rats. $¥$ Clin Invest 1982;70:1300-5.

62 Schaible TF, Scheuer J. Cardiac adaptations to chronic exercise. Prog Cardiovasc Dis 1985;27:297-324. 